\title{
Correction to: The Palgrave Handbook of Anti-Communist Persecutions
}

\author{
Christian Gerlach and Clemens Six
}

\section{Correction to:}

C. Gerlach and C. Six (eds.), The Palgrave Handbook of Anti-Communist Persecutions, https://doi.org/10.1007/978-3-030-54963-3

The original version of this book was inadvertently published with a wrong author name and wrong open access chapter, which have been corrected: In Chapter "Introduction: Anti-Communist Persecutions in the Twentieth Century", the incorrect author name has been corrected. Also, instead of Chapter "Getting Hold of a Universe of Conspirators: Anti-Communist Panic, Fears of Subversion, and the Routine of Repression in Senegal's Early Postcolonial Secret Police (the Sûreté), 1962-1965", Chapter "How AntiCommunism Disrupted Decolonization: South Korea's State-Building Under US Patronage" was inadvertently published as open access. This has now been corrected. The corrections to the book have been updated with the changes.

The updated version of these chapters can be found at https://doi.org/10.1007/978-3-030-54963-3_1 https://doi.org/10.1007/978-3-030-54963-3_7 https://doi.org/10.1007/978-3-030-54963-3_8 